\title{
Nanoparticle-Mediated Photodynamic Therapy for Mixed Biofilms
}

\author{
Marina Usacheva, ${ }^{1}$ Buddhadev Layek, ${ }^{1}$ Saif S. Rahman Nirzhor, ${ }^{1}$ and Swayam Prabha ${ }^{1,2}$ \\ ${ }^{1}$ Department of Pharmaceutics, College of Pharmacy, University of Minnesota, 308 Harvard Street SE, Minneapolis, MN 55455, USA \\ ${ }^{2}$ Center for Translational Drug Delivery, University of Minnesota, 308 Harvard Street SE, Minneapolis, MN 55455, USA
}

Correspondence should be addressed to Swayam Prabha; prabh025@umn.edu

Received 4 May 2016; Revised 5 July 2016; Accepted 13 July 2016

Academic Editor: Jianxun Ding

Copyright (C) 2016 Marina Usacheva et al. This is an open access article distributed under the Creative Commons Attribution License, which permits unrestricted use, distribution, and reproduction in any medium, provided the original work is properly cited.

\begin{abstract}
Wounds associated with diabetes are difficult to heal and often stay unhealed, leading to higher morbidity and mortality in the diabetic population. A major barrier to the successful healing of chronic diabetic wounds is the presence of biofilm-mediated infections. In recent years, photodynamic therapy (PDT) has emerged as a promising treatment modality for the management of chronic wounds. The objective of the present study was to evaluate the effectiveness of toluidine blue- (TB-) loaded nanoparticlemediated PDT in eradicating antibiotic-resistant polymicrobial biofilms of Pseudomonas aeruginosa and methicillin-resistant Staphylococcus aureus in an in vitro model. Dioctyl sodium sulfosuccinate (aerosol OT, AOT)-alginate nanoparticles with high TB loading $(10.8 \pm 2.2 \%)$ were formulated using a double emulsification cross-linking method. TB nanoparticles induced effective killing of planktonic P. aeruginosa $\left(3.5 \log _{10}\right.$ CFU) and S. aureus $\left(>5 \log _{10}\right.$ CFU) and their combined biofilms $\left(2.8 \log _{10}\right.$ CFU for $P$. aeruginosa versus $3.4 \log _{10} \mathrm{CFU}$ for $S$. aureus). While $P$. aeruginosa biofilm was more resistant when compared to that of $S$. aureus, our results demonstrated effective eradication of complex biofilms of dual bacterial strains in vitro.
\end{abstract}

\section{Introduction}

Chronic wounds are a major health problem throughout the world, with limited effective methods of treatment. Wounds associated with diabetes are difficult to heal and often remain unhealed leading to increased morbidity and mortality in diabetic patients $[1,2]$. A key barrier to the successful healing of chronic diabetic wounds is the presence of biofilm-mediated infections [3-5]. Biofilms are structured communities of microorganisms growing on a living or nonliving surface and enclosed in a self-produced matrix of extracellular polymeric substances (EPS) $[6,7]$. The matrix provides enormous protection to the biofilm against hostile environmental conditions, such as host immunological system and antimicrobial agents [8-11]. The polymicrobial nature of diabetic wounds appears to promote the production of several virulence factors that contribute to the chronicity of the infection $[12,13]$. In addition, presence of antibioticresistant bacteria such as methicillin-resistant Staphylococcus aureus (MRSA) and Pseudomonas aeruginosa (P. aeruginosa) is more common in diabetic wounds [14].
In recent years, photodynamic therapy (PDT) has emerged as a promising alternative treatment for the management of chronic infections. PDT is based on the concept that certain compounds, known as photosensitizers, when exposed to light of a specific wavelength, are capable of generating reactive oxygen species (ROS), such as singlet oxygen and free radicals [15-18]. Subsequently, ROS mediate cellular toxicity via oxidative stress to cell membranes and other cellular components $[19,20]$. One of the key advantages of PDT as a therapeutic tool is the concept of dual selectivity. Collateral damage to normal tissues can be reduced by the preferential accumulation of photosensitizers in the target tissue and localized light irradiation in a spatially focused manner [21].

Phenothiazine dyes such as methylene blue (MB) [22] and toluidine blue (TB) [23] have been extensively used for PDT-mediated eradication of a wide range of Grampositive and Gram-negative bacteria as well as fungi. The high quantum yield of singlet oxygen production [24, 25] coupled with relatively low dark toxicity $[26,27]$ makes them attractive candidates for PDT. However, several studies 
have demonstrated incomplete destruction of biofilms using MB [28, 29] and TB-mediated PDT [30]. The diminished susceptibility of biofilms to PDT was primarily attributed to poor penetration of the photosensitizer inside the cells $[28,29]$. Furthermore, both $\mathrm{MB}$ and $\mathrm{TB}$ are substrates of bacterial multidrug resistance efflux pumps, thus reducing the efficiency of these photosensitizers [31].

Therefore, a potential strategy to improve the efficacy of photosensitizers is to encapsulate them in a suitable drug carrier such as nanoparticles. Photosensitizers encapsulated in nanoparticles offer several distinct advantages over free photosensitizing molecules, which include increased accumulation of the photosensitizer in the target cells, and inhibition of target cell's ability to pump out the photosensitizers [32]. Furthermore, incorporation of the photosensitizer in nanoparticles could prevent the inactivation of photosensitizer by plasma reductases and thus protects its photodynamic activity [33]. In this study, the nanoparticles were formulated using anionic surfactant dioctyl sodium sulfosuccinate (aerosol OT, AOT) and a naturally occurring polysaccharide sodium alginate. Besides being nontoxic, the AOT-alginate nanoparticles have also been shown to improve ROS yield of photosensitizers [34]. The objective of the present study was to investigate the in vitro photodynamic efficacy of TB-loaded nanoparticles against both planktonic and biofilm phases of $P$. aeruginosa, MRSA, and their mixed culture. In addition, the in vitro photobactericidal efficacy of TB nanoparticles was compared with that of free TB.

\section{Materials and Methods}

2.1. Materials. TB, polyvinyl alcohol (PVA), sodium alginate, and bovine serum albumin (BSA) were purchased from Sigma-Aldrich (St. Louis, MO, USA). AOT and chloroform were procured from Fisher Scientific (Chicago, IL, USA). Luria Broth (LB) medium and LB agar medium were purchased from MP Biomedicals, LLC (Solon, Ohio, USA). P. aeruginosa (ATCC 27853) was received from Dr. Karunya Kandimalla (Department of Pharmaceutics, University of Minnesota, Minneapolis, MN) and S. aureus (ATCC 33591) from Dr. Christine Salomon (Center for Drug Design, University of Minnesota, Minneapolis, MN). All other reagents are chemical grade and used without further modification.

2.2. Nanoparticle Formulation. AOT-alginate nanoparticles encapsulating TB were prepared using a double emulsification cross-linking method $[35,36]$. Briefly, $1 \mathrm{~mL}$ of $1 \% \mathrm{w} / \mathrm{v}$ aqueous sodium alginate solution containing $5 \mathrm{mg}$ of TB was emulsified into $2 \mathrm{~mL}$ of $2 \% \mathrm{w} / \mathrm{v}$ AOT solution in chloroform by sonication at $20 \mathrm{~W}$ for $5 \mathrm{~min}$ over an ice bath (Model W-375, Heat Systems Ultrasonics Inc., CT). The water-inoil (w/o) primary emulsion was re-emulsified into $15 \mathrm{~mL}$ of $2 \% \mathrm{w} / \mathrm{v}$ aqueous PVA solution to form a water-in-oil-inwater $(\mathrm{w} / \mathrm{o} / \mathrm{w})$ multiple emulsion. To the final emulsion, $5 \mathrm{~mL}$ of $60 \% \mathrm{w} / \mathrm{v}$ aqueous calcium chloride solution was added dropwise with constant stirring at $1200 \mathrm{rpm}$ using a magnetic stirrer. Subsequently, chloroform was evaporated by continuously stirring the emulsion at ambient conditions for $18 \mathrm{~h}$ followed by $1.5 \mathrm{~h}$ stirring under vacuum. The nanoparticles were harvested by ultracentrifugation at $35000 \mathrm{rpm}$ for $30 \mathrm{~min}$ (Beckman Optima $^{\mathrm{TM}}$ LE-80K, Palo Alta, CA), washed three times with deionized water to eliminate excess PVA and unentrapped TB. After the final wash, the nanoparticle pellet was redispersed in $1 \mathrm{~mL}$ of deionized water, and nanoparticles were separated from large aggregates by centrifugation at $1000 \mathrm{rpm}$ for $5 \mathrm{~min}$ (Eppendorf ${ }^{\circledR} 5810 \mathrm{R}$, Eppendorf, Westbury, NY). The supernatant nanoparticle suspension was then freeze dried (FreeZone $4.5^{\circledR}$, Labconco, Kansas City, $\mathrm{MO})$ to obtain dry nanoparticles. Blank nanoparticles were synthesized in the absence of TB.

2.3. Nanoparticle Characterization. The average hydrodynamic diameter and zeta potential of the nanoparticles were measured using a Delsa ${ }^{\text {тм }}$ Nano $C$ particle size analyzer (Beckman Coulter Inc., Fullerton, CA) equipped with dual $30 \mathrm{~mW}$ laser diodes operating at $658 \mathrm{~nm}$ wavelength and at $165^{\circ}$ constant scattering angle. One milligram of nanoparticles was dispersed in $4 \mathrm{~mL}$ of deionized water with sonication and then used for analysis.

To determine TB loading, nanoparticles were dispersed in methanol at a concentration of $1 \mathrm{mg} / \mathrm{mL}$, incubated in dark for $1 \mathrm{~h}$, and then centrifuged at $13000 \mathrm{rpm}$ for $20 \mathrm{~min}$. The absorbance of the methanol extract was measured at $626 \mathrm{~nm}$ using a Cary-100 UV-vis spectrophotometer. The concentration of TB was quantified from a standard curve constructed with known concentrations of TB in methanol. The experiment was conducted in replicates of four.

2.4. Bacterial Uptake of Nanoparticles. The microbial uptake of TB nanoparticles in the absence or presence of BSA $(0.06 \%$ and $0.15 \% \mathrm{w} / \mathrm{v})$ was studied using planktonic $P$. aeruginosa. Free TB served as a control for this study. Free or nanoparticle-encapsulated TB at an equimolar dye concentration $(100 \mu \mathrm{M})$ was added to the bacterial suspensions $\left(5 \times 10^{8} / \mathrm{mL}\right)$ and incubated in the dark for $1 \mathrm{~h}$ at room temperature with gentle shaking at $125 \mathrm{rpm}$. Subsequently, the bacterial suspensions were centrifuged at $1000 \mathrm{rpm}$ for 10 min to allow sedimentation of the TB-bound bacteria. Following two washes in phosphate-buffered saline (PBS), the cell bound TB was extracted with methanol for $1 \mathrm{~h}$ at room temperature and then centrifuged at $13000 \mathrm{rpm}$ for $20 \mathrm{~min}$. The amount of TB in the supernatant was quantified spectrophotometrically at $626 \mathrm{~nm}$ using a calibration curve of pure TB in PBS. The experiment was performed in triplicate. The extent of bacterial uptake of TB was calculated by the following equation:

Nanoparticle uptake (\%)

$$
=\frac{\text { Amount of TB in the dissolved pellet }}{\text { Total amount of TB added }} \times 100 \text {. }
$$

2.5. In Vitro Release Study. The release profile of $\mathrm{TB}$ from AOT-alginate nanoparticles was assessed in PBS at $\mathrm{pH}$ 7.4. Nanoparticle suspension $(5 \mathrm{~mL}, 1 \mathrm{mg} / \mathrm{mL})$ was incubated at $37^{\circ} \mathrm{C}$ and $125 \mathrm{rpm}$ in a benchtop incubator shaker (Brunswick Scientific, C24 incubator shaker, NJ). At each time point, $0.5 \mathrm{~mL}$ of nanoparticle suspension was 
centrifuged at $13000 \mathrm{rpm}$ for $20 \mathrm{~min}$ and the concentration of released TB in the supernatant was determined spectrophotometrically at $626 \mathrm{~nm}$ using a calibration curve of pure TB in methanol. The experiment was performed in replicates of four.

2.6. Bacterial Strains and Culture. P. aeruginosa and S. aureus were used in this study. The day prior to the test, fresh bacterial cultures were grown aerobically on trypticase soy agar for $24 \mathrm{~h}$ at $37^{\circ} \mathrm{C}$. On the day of the experiment, the bacteria were harvested by centrifugation and suspended in $1 x$ PBS.

\subsection{Photodynamic Treatment of Planktonic Bacteria. The} PDT experiments were conducted on the $P$. aeruginosa and $S$. aureus cultured in the separated and the mixed culture. Bacterial cell suspensions in PBS were incubated with $100 \mu \mathrm{M}$ of free or nanoparticle-encapsulated $\mathrm{TB}$ in the dark for $30 \mathrm{~min}$ at room temperature while shaking at $125 \mathrm{rpm}$. Following incubation, the cell suspensions were centrifuged at $13000 \mathrm{rpm}$ for $5 \mathrm{~min}$, washed twice, and the pellet was resuspended in sterile PBS. Subsequently, aliquots of $0.7 \mathrm{~mL}$ of the cell suspensions were placed in the wells of 24-well plates. Excluding the dark controls, the wells were irradiated with red light $\left(\lambda_{665 \mathrm{~nm}}\right)$ using an Osram halogen lamp integrated into LumaCare ${ }^{\mathrm{TM}}$ LC-122 fiber optic light delivery device (Newport Beach, CA) for $25 \mathrm{~min}$. The light exposure was from the top and the distance between the exposed sample and the light source tip was fixed to obtain a constant fluence rate. An average effective fluence rate of $17 \mathrm{~mW} / \mathrm{cm}^{2}$ was measured using an Orion PD energy meter. The entire well plate was kept covered during the irradiation in order to preserve the purity of the culture. After irradiation, the bacterial suspensions underwent serial dilutions in LB media, and $100 \mu \mathrm{L}$ of the samples was seeded on LB agar plates. The number of colony forming units (CFUs) was counted after $48 \mathrm{~h}$ of incubation at $37^{\circ} \mathrm{C}$ and expressed as $\log _{10} \mathrm{CFU} / \mathrm{mL}$. The following experimental groups were used: (1) L-TB-: positive control (microbial pool); (2) L-TB free+: microbial pool incubated with $100 \mu \mathrm{M}$ of TB solution in the dark for $30 \mathrm{~min}$; (3) L-TB NP+: microbial pool incubated with $100 \mu \mathrm{M}$ of TB NP formulation in the dark for $30 \mathrm{~min}$; (4) L+TB free+: microbial pool incubated with $100 \mu \mathrm{M}$ of TB solution in the dark for $30 \mathrm{~min}$ and then exposed to red light; and (5) L+TB NP+: microbial pool incubated with $100 \mu \mathrm{M}$ of TB NP formulation in the dark for $30 \mathrm{~min}$ and then exposed to red light. Each of these treatments was performed in replicates of four.

2.8. Preparation of Biofilms. Biofilms of P. aeruginosa, $S$. aureus, and their mixtures were grown on commercially available polycarbonate coupons using a CDC Bioreactor (Biosurface Technologies, Bozeman, Montana). Initially, all reactor parts including rods, baffle, coupons, bacterial air vent, and tubing were autoclaved and assembled according to the manufacturer's protocol. The coupons were then positioned in the coupon holes in each plastic reactor rod and firmly secured by screws. To initiate biofilm formation, $400 \mathrm{~mL}$ of $0.3 \mathrm{mg} / \mathrm{mL}$ sterile $\mathrm{LB}$ media was added to the reactor chamber ensuring that each coupon was completely immersed. This low concentration of LB media provided a nutrient depleted condition within the reactor. After that, $1 \mathrm{~mL}\left(5 \times 10^{8} \mathrm{CFU} / \mathrm{mL}\right)$ of an overnight bacterial culture (single or mixed) was transferred aseptically to the reactor chamber to confirm that bacteria were in the log phase. Immediately after inoculation with bacterial culture, the reactor was set to stir at $125 \mathrm{rpm}$. Subsequently, the biofilm was allowed to form at room temperature for $24 \mathrm{~h}$ in batch phase while the baffle rotated. To facilitate steady state biofilm formation, the reactor was operated for an additional $24 \mathrm{~h}$ with continuous flow of LB medium $(0.135 \mathrm{mg} / \mathrm{mL})$ at a rate of $15 \mathrm{~mL} / \mathrm{min}$. In continuous phase the reactor was maintained at $37^{\circ} \mathrm{C}$ and $125 \mathrm{rpm}$. Finally, the biofilms grown on coupons were removed from the reactor rod aseptically, rinsed with sterile PBS to eliminate any planktonic cells, and stored in sterile PBS.

2.9. Photodynamic Treatment of Biofilms. The freshly prepared biofilms containing coupons were randomly assigned to the different groups as mentioned under Section 2.8. Coupons were then placed into separate wells of a sterile 24well plate containing $1 \mathrm{~mL}$ of TB formulation in PBS, while the control coupons were incubated with sterile PBS alone. Following $30 \mathrm{~min}$ of dark incubation at room temperature, each side of the coupon was exposed to red light $\left(\lambda_{665 \mathrm{~nm}}\right)$ with a fluence rate of $17 \mathrm{~mW} / \mathrm{cm}^{2}$ and a total light fluence of $25.5 \mathrm{~J} / \mathrm{cm}^{2}$ as described above. After irradiation, adherent bacteria were gently scraped with a sterile cell lifter, resuspended in $10 \mathrm{~mL}$ of $\mathrm{PBS}$, and serial dilutions were prepared in LB media. Lastly, $100 \mu \mathrm{L}$ aliquots were inoculated onto LB agar plates and the number of CFUs was counted after $48 \mathrm{~h}$ of incubation at $37^{\circ} \mathrm{C}$.

2.10. Spectral Characteristics of TB. The bactericidal effectiveness of a photosensitizer is strongly influenced by its structural conformation and electron absorption spectrum [37]. Therefore, the structural integrity of TB extracted from nanoparticles was confirmed by recording its absorbance spectra in the visible region $(400-700 \mathrm{~nm})$. The UV-spectra of free TB in methanol were used as a control. Further, the integrity of free TB or that encapsulated in nanoparticles was also evaluated under experimental conditions (i.e., at $100 \mu \mathrm{M}$ concentration in PBS) by measuring their absorption spectra in the visible region, where the monomer, dimer, and aggregates bands of the TB were distinct.

2.11. Statistical Analysis. Statistical analysis of bacterial uptake of nanoparticles was performed using two-tailed Student's $t$-test. Statistical analyses for photodynamic treatments were performed using two-way analysis of variance (ANOVA) by Tukey's test for comparison between individual groups. A probability level of $p<0.05$ was considered significant.

\section{Results and Discussion}

Biofilm related infections continue to pose major global health problems due to lack of effective treatments [38]. 


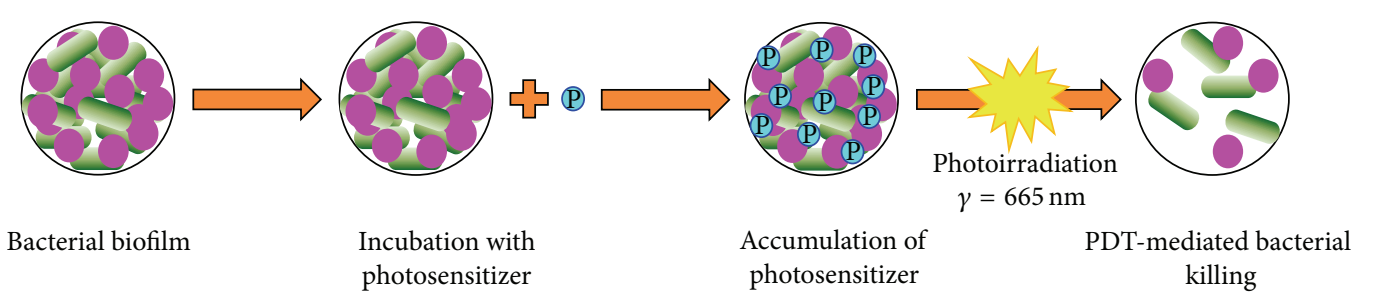

P. aeruginosa
S. aureus
(P) Photosensitizer

FIGURE 1: Schematic representation of PDT-mediated bacterial killing.

Biofilm-embedded bacteria are difficult to treat, as they are often resistant to antibiotics and the host immune system. PDT has evolved as a potential alternative therapeutic strategy since this modality is not susceptible to resistance mechanisms found in bacteria [39]. However, poor microbial uptake of the photosensitizer due to the viscosity barrier created by EPS contributes to less than optimal photobactericidal efficacy $[40,41]$. Recently, polymeric nanoparticles have received increasing attention as promising delivery tools to enhance the therapeutic efficacy of encapsulated photosensitizers $[22,42]$. The use of a matrix-type nanoparticle system can potentially allow better interaction of the photosensitizer with the matrix as well as with neighboring photosensitizer molecules and thereby facilitate efficient electron transfer. Previous studies demonstrated that AOT-alginate nanoparticles efficiently encapsulated weakly basic polar molecules such as MB [43]. Furthermore, the use of sodium alginate allows high local concentration of water in the vicinity of the photosensitizer which may assist efficient electron transfer and production of hydroxyl radical [44]. The general scheme of PDT-mediated bacterial killing is shown in Figure 1.

3.1. Formulation and Characterization of Nanoparticles. TB was encapsulated into AOT-alginate nanoparticles using a double emulsification cross-linking method. The hydrodynamic diameter of the nanoparticles, characterized by dynamic light scattering, was $215 \pm 24 \mathrm{~nm}$. The polydispersity index of the nanoparticles was less than 0.2 , suggesting a fairly narrow size distribution. As indicated by the electrophoretic light scattering analysis, nanoparticles had a net negative surface charge of $-21.2 \pm 4.3$. The negative zeta potential is ascribed to the presence of anionic sulfonate groups of AOT and the carboxyl groups of alginate [43]. TB loading in nanoparticles was $10.8 \pm 2.2 \% \mathrm{w} / \mathrm{w}$.

3.2. Bacterial Uptake of Nanoparticles. The binding of photosensitizer to the bacterial cell membrane or its uptake into the cells during incubation with TB (free or encapsulated in nanoparticles) is an important determinant in PDT-mediated bacterial killing. It is a well-known fact that the presence of charged molecules such as albumin could adversely influence the binding of photosensitizer or nanoparticles with bacterial cells, which in turn can diminish the antibacterial activity [45]. Hence, the TB binding efficiency of planktonic $P$. aeruginosa was determined in the absence or presence of BSA. Albumin is the most common protein in blood and inflammatory exudates [46]. Selected BSA concentrations of $0.06 \%$ and $0.15 \%$ resemble the actual albumin concentration in chronic and acute wounds, respectively [47]. As shown in Figure 2(a), the fraction of TB bound to bacterial cells was significantly $(p<0.05)$ higher in the nanoparticle group as compared to that for the free dye treatment. After $1 \mathrm{~h}$ of dark incubation at room temperature, about $39.4 \%$ of the TB encapsulated in nanoparticles was bound to the bacteria while only $22.7 \%$ association was observed for TB solution in PBS. Addition of low level of BSA $(0.06 \% \mathrm{w} / \mathrm{v})$ in the medium did not affect the bacterial binding of TB either from TBloaded nanoparticles or from TB solution. Nevertheless, the bacterial binding of TB solution was found to be severely compromised in the presence of $0.15 \% \mathrm{w} / \mathrm{v}$ of BSA. Therefore, encapsulation of $\mathrm{TB}$ is important for enhancing bacterial binding under in vivo conditions where the presence of serum proteins could significantly inhibit the association of free TB.

3.3. In Vitro Release Study. In vitro release of nanoparticleencapsulated TB was performed under sink condition. An initial burst release of $9.6 \%$ of $\mathrm{TB}$ was observed at the end of $0.5 \mathrm{~h}$ (Figure 2(b)). The total release over 7 days was $18.5 \%$. The sustained release profile of TB could be attributed to electrostatic interactions between weakly basic TB and anionic nanoparticle matrix [35]. For PDT experiments, both the planktonic and biofilm-embedded bacteria were incubated with nanoparticles in the dark for $30 \mathrm{~min}$ at room temperature, which imply that only $9.6 \%$ of TB was available for PDT-mediated bacterial killing. Furthermore, the sustained release profile of TB from alginate nanoparticles offers the possibility of repeated exposure to phototherapy after single administration of nanoparticles. These results clearly demonstrate the advantages of the nanoparticle formulation over free dye.

3.4. PDT of Planktonic Bacteria. Although the microflora of chronic wounds is typically polymicrobial and heterogeneous, $S$. aureus and $P$. aeruginosa are the most common bacteria isolated from these wounds [48-50]. These two bacteria are frequently found together and often cause biofilm-mediated infections in their hosts. Therefore, the efficacy of the TB-mediated PDT was evaluated against both 


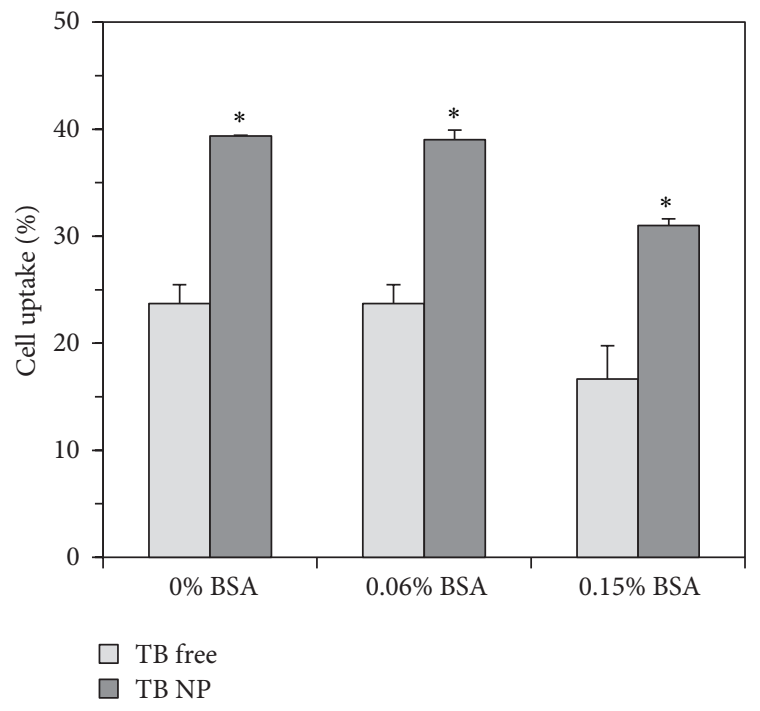

(a)

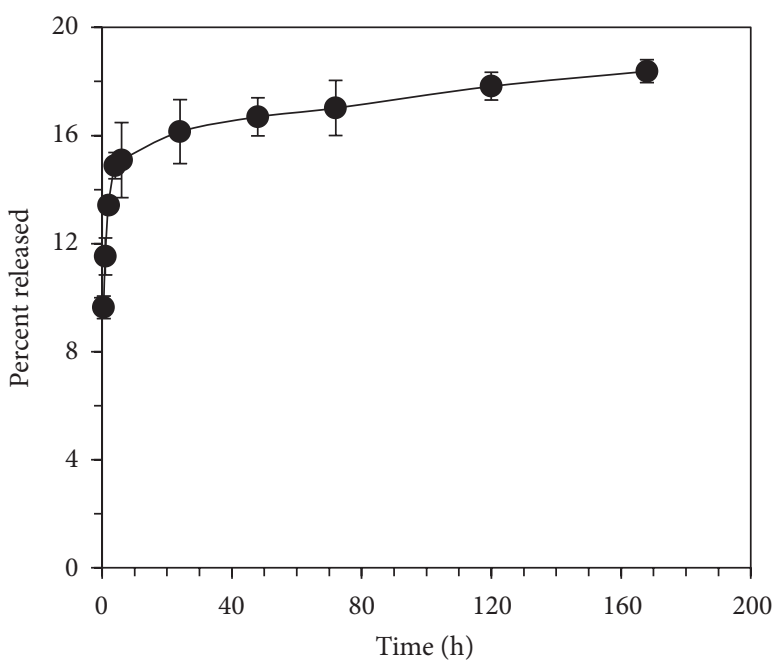

(b)

Figure 2: (a) Comparison of bacterial uptake of free and nanoparticle-encapsulated TB. Data represents mean $\pm \mathrm{SD}, n=3$. ${ }^{*} p<0.05$ compared to respective TB free group; (b) in vitro release profile of TB in PBS at $37^{\circ} \mathrm{C}$ and $125 \mathrm{rpm}$. Data represents mean $\pm \mathrm{SD}(n=4)$.

planktonic and biofilm phases of $P$. aeruginosa, S. aureus, and their mixed culture. The results of the planktonic PDT experiments are depicted in Figure 3. Without TB treatment, bacterial samples (L+TB-) exhibited normal growth, suggesting that the selected irradiation dose (fluence rate $17 \mathrm{~mW} / \mathrm{cm}^{2}$, total fluence $25.5 \mathrm{~J} / \mathrm{cm}^{2}$ ) alone had no antibacterial effects (Figure 3(a)). Similarly, without irradiation, incubation of bacterial suspension with $100 \mu \mathrm{M}$ of free TB or $\mathrm{TB}$ encapsulated nanoparticles (L-TB free+ or L-TB NP+) in the dark for $30 \mathrm{~min}$ did not induce killing. This indicates that TB nanoparticles or free TB did not exert dark toxicity against $P$. aeruginosa. In contrast, irradiation of $P$. aeruginosa in the presence of $100 \mu \mathrm{M}$ of TB free or encapsulated in nanoparticles ( $\mathrm{L}+\mathrm{TB}$ free+ and $\mathrm{L}+\mathrm{TB} \mathrm{NP}+$ ) resulted in a $3.5 \log _{10}$ CFU reduction in the viable counts (Figure 3(a)), which demonstrates the feasibility of TB-mediated PDT for the treatment of $P$. aeruginosa infection.

Likewise, the incubation of $S$. aureus with TB encapsulated nanoparticles (equivalent to $100 \mu \mathrm{M}$ of free TB) in the dark for 30 min exhibited no decrease in the number of CFU (Figure 3(b)). Irrespective of the bacterial species there were no significant $(p>0.05)$ differences between free TB and TB NP groups in single culture. However, the PDT group $(\mathrm{L}+\mathrm{TB}$ $\mathrm{NP}+$ ) exhibited complete killing of $S$. aureus ( $\left.>5 \log _{10} \mathrm{CFU}\right)$. These results are in agreement with the existing literature suggesting $S$. aureus (Gram-positive) is more susceptible to photokilling compared to Gram-negative P. aeruginosa [51]. This is due to the differences in their membrane structure. Gram-positive bacteria have a relatively porous layer of peptidoglycan and a single lipid bilayer, which allows greater diffusion of the photosensitizer into the bacterial cell [52]. Therefore, they can be eradicated by a wide range of dyes and at lower doses of irradiation, which explains the higher susceptibility of $S$. aureus to PDT in our study [51]. On the other hand, Gram-negative bacteria comprise a double lipid bilayer sandwiching the peptidoglycan layer and an outer lipopolysaccharide layer, which act as an efficient barrier to limit permeability of various substances [17].

In the mixed suspension, as expected, the potency of PDT was found to be higher for $S$. aureus as compared to $P$. aeruginosa (Figure $3(\mathrm{c})$ ). In contrary to single culture, the photokilling efficiency of free TB was marginally $(p=0.034$ for $S$. aureus and $p=0.048$ for $P$. aeruginosa) higher than that of TB nanoparticles. The lower efficacy of nanoparticleencapsulated TB compared to free $\mathrm{TB}$ is associated with the competitive extraction of the dye from nanoparticles compared to the dye interaction with bacteria. However, the overall bacterial killing rate in mixed suspension was low as compared to their single culture PDT, probably due to synergy between $S$. aureus and $P$. aeruginosa $[53,54]$. It has to be further noted that we used same amount of TB dose in mixed culture as that used in the isolated individual cultures of each strain. Since there is almost double the amount of species present for the same amount of $\mathrm{TB}$, it is anticipated that there will be diminished overall bacterial killing efficiency.

3.5. PDT of Bacterial Biofilm. The biofilms were incubated with either $100 \mu \mathrm{M}$ TB free or TB encapsulated nanoparticles for $30 \mathrm{~min}$ in dark at room temperature. Following dark incubation, each side of the coupon was exposed to red light $\left(\lambda_{665 \mathrm{~nm}}\right)$ with a fluence rate of $17 \mathrm{~mW} / \mathrm{cm}^{2}$ and a total light fluence of $25.5 \mathrm{~J} / \mathrm{cm}^{2}$. The results of the biofilm PDT experiments are shown in Figure 4. Free TB or TB encapsulated nanoparticles did not exhibit dark toxicity against $P$. aeruginosa, $S$. aureus, and their mixed biofilms. However, irradiation of $P$. aeruginosa biofilm in the presence of free TB (L+TB free+) and TB encapsulated nanoparticles $\left(\mathrm{L}+\mathrm{TB} \mathrm{NP}+\right.$ ) resulted in $2.5 \log _{10} \mathrm{CFU}$ and $2.8 \log _{10} \mathrm{CFU}$ reduction in the viable counts, respectively (Figure 4(a)). 


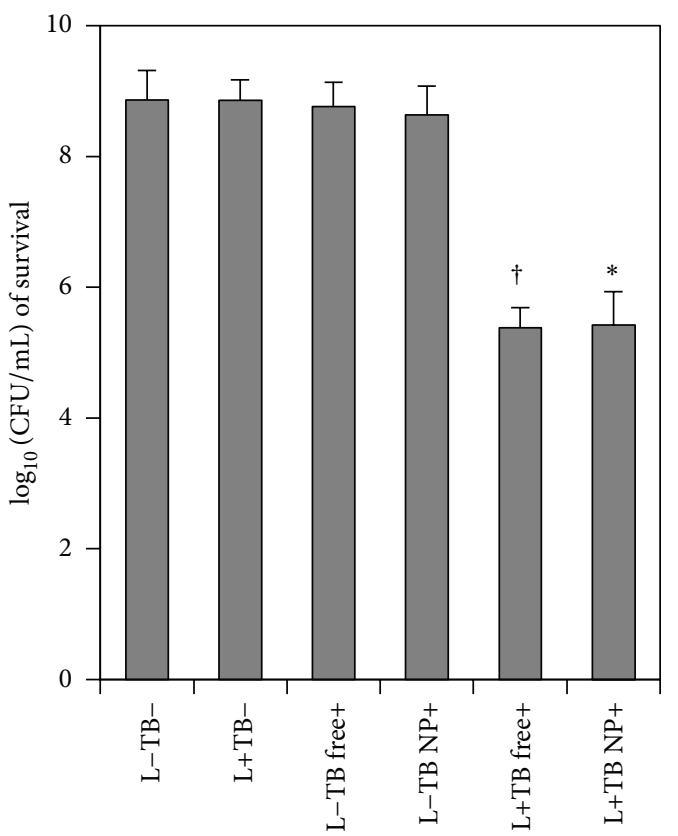

(a)

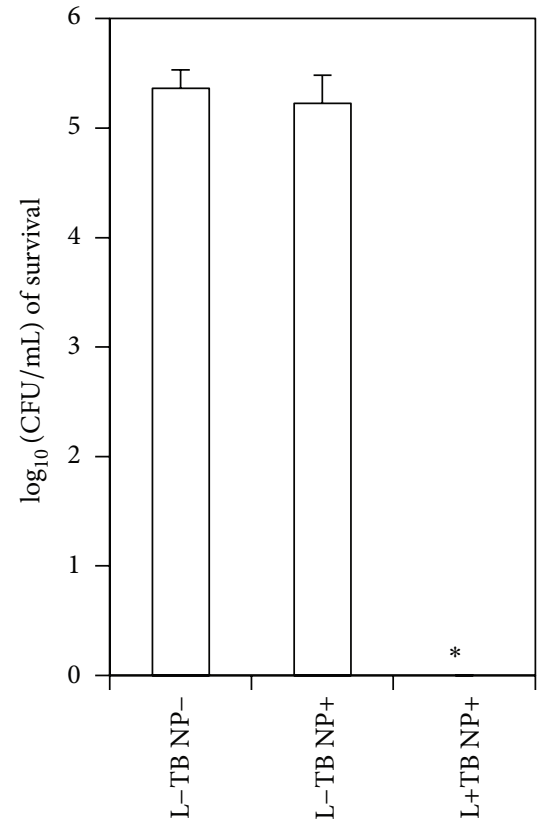

(b)

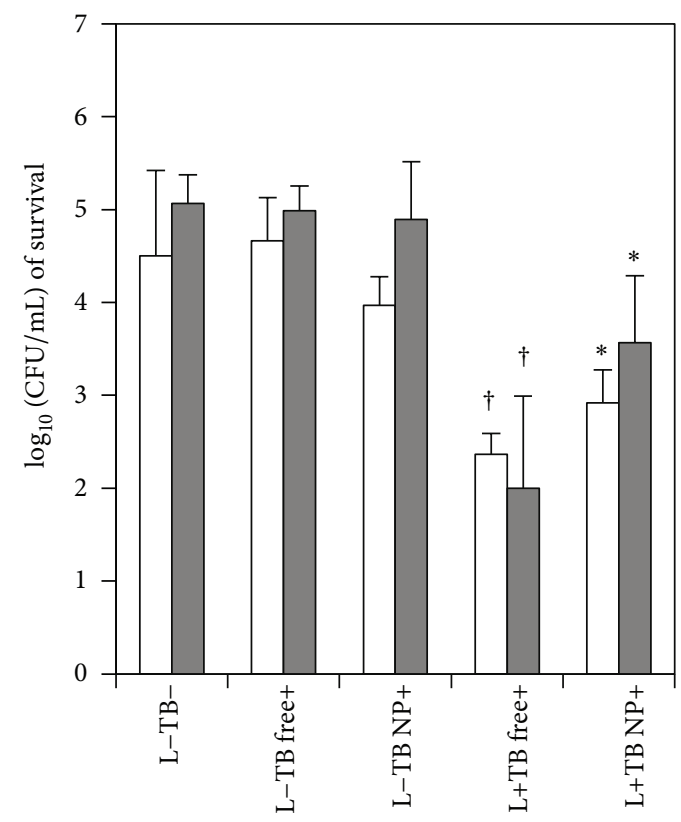

$\square$ S. aur

$\square$ P. aer

(c)

Figure 3: Survival $\left(\log _{10}\right.$ CFU) of planktonic (a) P. aeruginosa, (b) S. aureus, and (c) mixed suspension P. aeruginosa and S. aureus after treatments with PBS, free TB, or TB-loaded alginate nanoparticles in the presence or absence of light $\left(\lambda_{665 \mathrm{~nm}}\right){ }^{*} p<0.05$ compared to respective TB NP control group and ${ }^{\dagger} p<0.05$ compared to respective TB free control group.

Moreover, the efficiency of PDT on biofilms was found to be strain dependent. For $S$. aureus biofilm, PDT group $(\mathrm{L}+\mathrm{TB} \mathrm{NP}+)$ induced a $3.4 \log _{10} \mathrm{CFU}$ reduction in bacterial count (Figure 4(b)). As expected, in the mixed biofilm, the reduction of $S$. aureus was greater than that observed for P. aeruginosa (Figure 4(c)). However, mean $\log _{10}$ CFU level of free TB was not significantly different from that of TB NPs.

The results of PDT experiments clearly demonstrated that the photosensitivity of planktonic bacteria was higher than bacteria within biofilms. Several factors have been found to be responsible for biofilm resistance that include slow growth 


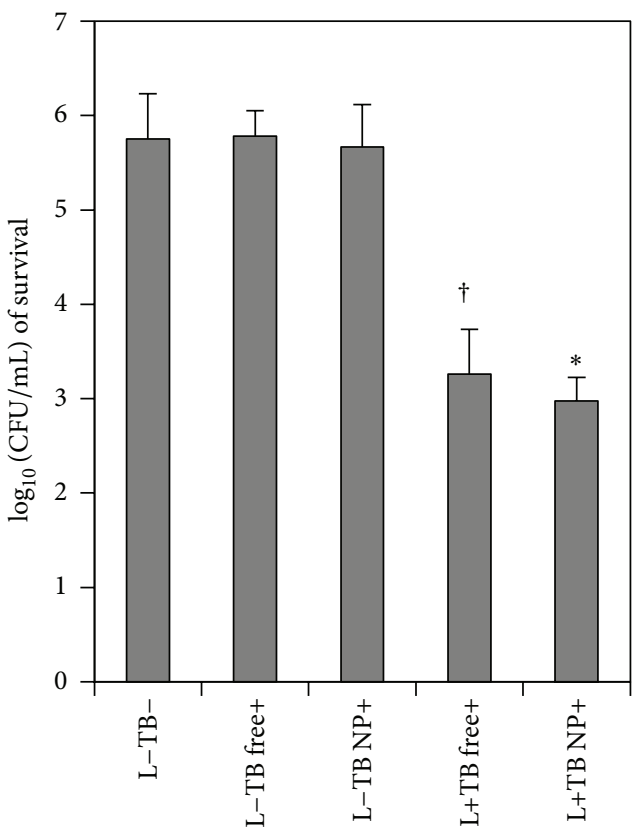

(a)

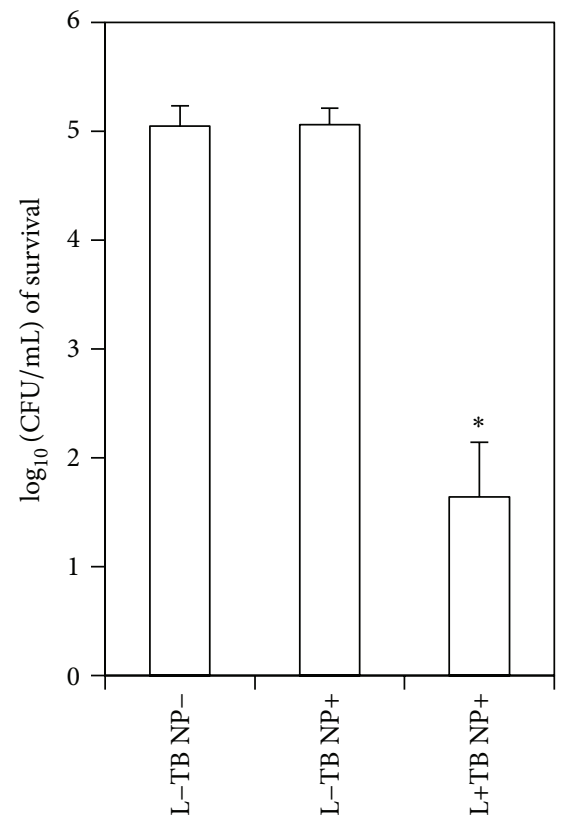

(b)

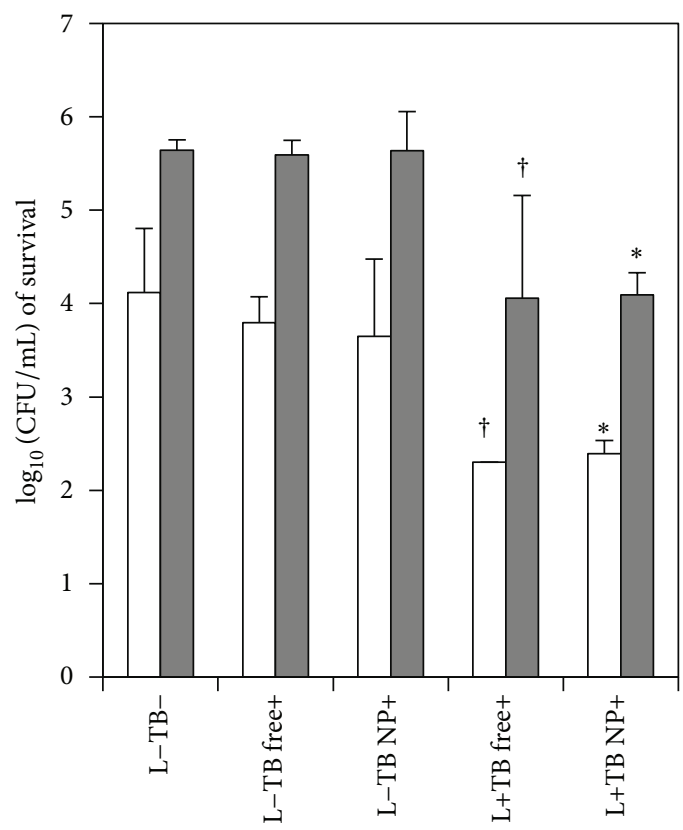

S. aur

P. aer

(c)

FIGURE 4: Survival ( $\log _{10}$ CFU) of biofilm-based (a) P. aeruginosa, (b) S. aureus, and (c) mixture of P. aeruginosa and S. aureus after treatments with PBS, free TB, or TB-loaded alginate nanoparticles in the presence or absence of light $\left(\lambda_{665 \mathrm{~nm}}\right) .{ }^{*} p<0.05$ compared to respective TB NP control group and ${ }^{\dagger} p<0.05$ compared to respective TB free control group.

rate compared to planktonic cultures, differences in cell wall composition, and the presence of EPS matrix in biofilm cultures [30]. It has been demonstrated that the higher viscosity of the EPS matrix results in diminished diffusion of photosensitizer and hence its association with bacterial cells in addition to increased hindrance to the penetration of light and hence photosensitization of the biofilms [30, 40]. Further, the EPS-matrix molecules are capable of reacting with diverse antimicrobials/photosensitizers via electrostatic interactions or through $\pi$ - $\pi$-interactions of aromatic moieties, thus inhibiting the penetration of these molecules into deeper parts of the biofilm [40]. 


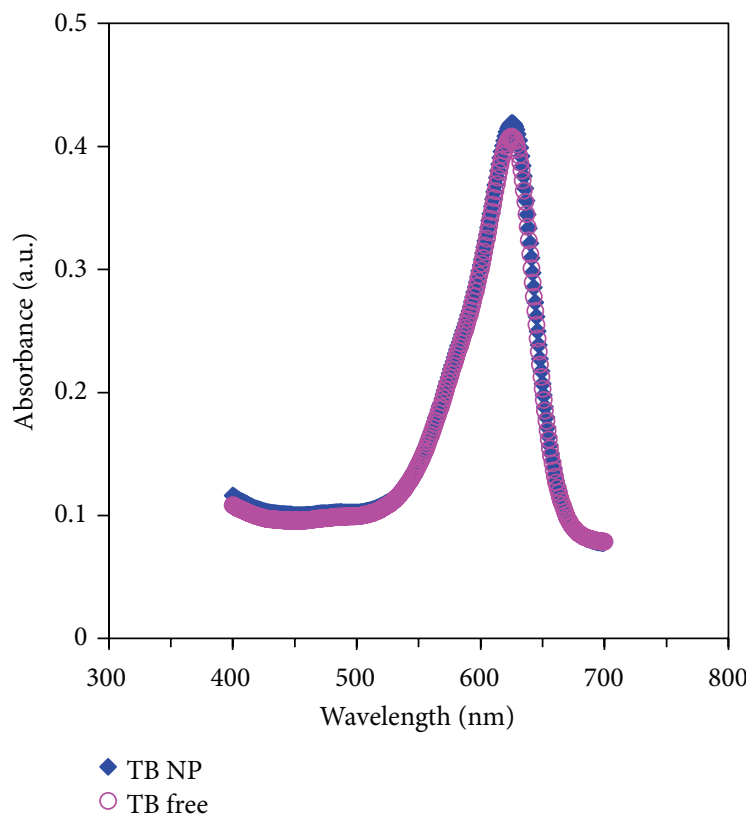

(a)

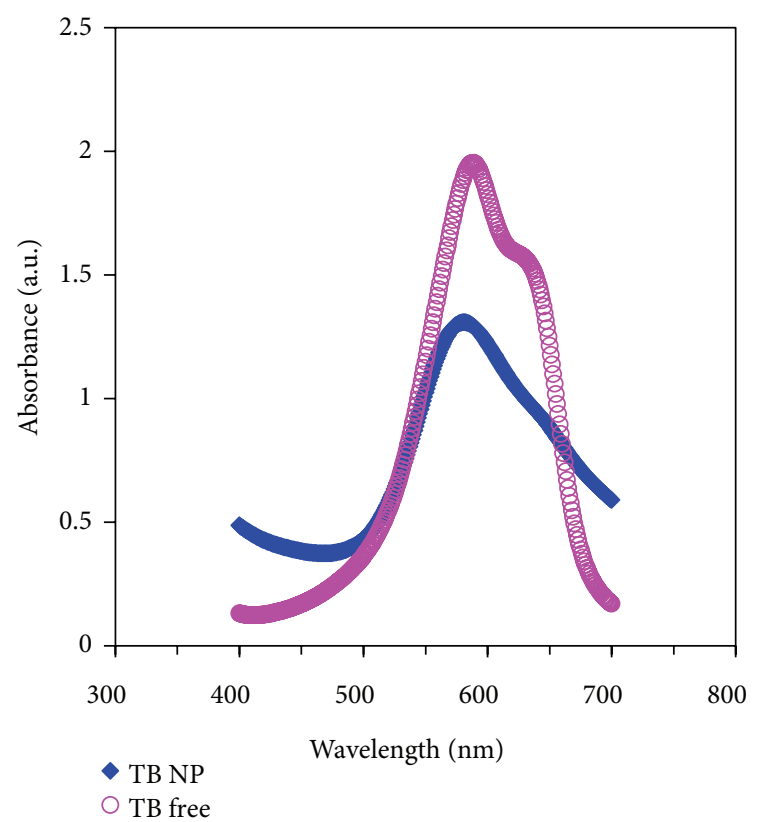

(b)

FIGURE 5: UV-vis spectrum of TB free and TB NP at (a) $6.86 \mu \mathrm{M}$ methanol solution and (b) $100 \mu \mathrm{M}$ PBS solution.

Contrary to the expectations, our data reveal not significantly different $(p>0.05)$ photobactericidal efficacy of TB free and TB encapsulated in sodium alginate nanoparticles against bacteria grown both planktonically and in biofilm (Figures 3 and 4). Several factors could explain the observed photokilling activities in our experiments. TB, a cationic dye, likely interacts with anionic polymers via electrostatic (Coulomb) interactions, resulting in the generation of metachromatic complex dimers and trimers [55]. In order to understand the mechanism of reduced efficacy of nanoparticles, we studied the changes in the conformation of TB encapsulated inside nanoparticles. The spectral characteristics of free TB and TB encapsulated nanoparticles are shown in Figure 5. As depicted in Figure 5(a), there was no observable difference in the absorption spectra of free TB and TB extracted from nanoparticles in methanol. Regardless of the formulation type (free or nanoparticle encapsulated), TB existed as a monomer in methanol as shown by a single peak at $626 \mathrm{~nm}$. These results clearly indicate that there is no difference in the structural conformation of the dye when it is encapsulated in the nanoparticles. However, in the presence of PBS, the absorbance maxima of TB bound to nanoparticles was shifted toward the shorter wavelengths of the spectrum, suggesting the formation of dye dimers and higher aggregates. In contrast, free TB appeared as both dimer and monomer as demonstrated by the presence of two peaks at $626 \mathrm{~nm}$ and $590 \mathrm{~nm}$. As reported earlier, the negatively charged nanoparticle matrix could induce dimer formation of positively charged TB [44]. Subsequently, the aggregated $\mathrm{TB}$ would decrease the quantum yield of singlet oxygen, resulting in decreased bacterial killing [56].

Figure 5(b) demonstrates the induced TB dimer formation in alginate nanoparticles. The same kind of $\mathrm{TB}$ dimers can be produced on the surface of lipopolysaccharide (LPS), an anionic polymer found in the outer membrane of the Gram-negative bacteria. It was previously shown that the first step of photodynamic action of TB against Gram-negative bacteria is the formation of metachromatic complex between the dye and LPS, resulting in the damage of the outer membrane layer [57]. Additionally, the amount of dye available from the nanoparticles was only $10 \%$ of the free dye and still same effect was exerted suggesting superiority of nanoparticles in imparting toxicity at low doses.

However, TB-alginate nanoparticles have a number of potential advantages over free TB. Successful wound treatment requires a moist environment. Under these conditions, encapsulation inside alginate nanoparticles could improve the stability of the dye and sustained retention in bacterial biofilms (Figure 2(b)), whereas free TB could be cleared away with the wound fluid [58]. Thus, free TB may not be effective when repeated doses of PDT are required as in the case of chronic wounds where repeated exposure to phototherapy has been proven beneficial $[59,60]$. Furthermore, TB-sodium alginate nanoparticles are more resistant to the albumin environment than free TB (Figure 2(a)). The existence of metachromatic complex between TB and alginate eliminates the TB interaction with proteins. It is widely known that the free cationic dyes bound to plasma proteins have negligible bactericidal effect when photosensitized due to bound/hidden photosensitizer groups. Finally, sodium alginate is the polymer of choice due to its gelling ability, biocompatibility, biodegradability, and established use in wound dressings [61]. These factors along with the bactericidal efficacy of TB-alginate nanoparticles could result in effective in vivo wound treatment. 


\section{Conclusions}

In this paper, we studied the effect of TB-mediated PDT against biofilms of Gram-positive $P$. aeruginosa, Gramnegative $S$. aureus, and their mixed culture. The reduction of bacterial survival reached $3.4 \log _{10} \mathrm{CFU}$ for S. aureus and $2.8 \log _{10}$ CFU for P. aeruginosa biofilm, respectively. Greater photo bactericidal effect was observed in case of the Grampositive bacteria when compared to their Gram-negative counterpart. This could be attributed to the differences in the membrane structure of the two species and hence differences in uptake of the photosensitizer. Nanoparticles were equally effective, despite the availability of less free dye $(<10 \%$ of the encapsulated TB was released from the nanoparticles). Future studies evaluating the efficacy of nanoparticle-mediated PDT in vivo will substantiate the usefulness of this alternative treatment modality against antibiotic resistant chronic infections.

\section{Competing Interests}

There are no competing interests related to this paper.

\section{Acknowledgments}

The authors would like to greatly acknowledge the financial support provided by Center for Translational Drug Delivery, College of Pharmacy, University of Minnesota.

\section{References}

[1] K. Bakker and N. C. Schaper, "The development of global consensus guidelines on the management and prevention of the diabetic foot 2011," Diabetes/Metabolism Research and Reviews, vol. 28, supplement 1, pp. 116-118, 2012.

[2] V. Maida, M. Ennis, C. Kuziemsky, and J. Corban, "Wounds and survival in noncancer patients," Journal of Palliative Medicine, vol. 13, no. 4, pp. 453-459, 2010.

[3] T. Bjarnsholt, K. Kirketerp-Møller, P. Ø. Jensen et al., "Why chronic wounds will not heal: a novel hypothesis," Wound Repair and Regeneration, vol. 16, no. 1, pp. 2-10, 2008.

[4] S. E. Dowd, R. D. Wolcott, Y. Sun, T. McKeehan, E. Smith, and D. Rhoads, "Polymicrobial nature of chronic diabetic foot ulcer biofilm infections determined using bacterial tag encoded FLX amplicon pyrosequencing (bTEFAP)," PLoS ONE, vol. 3, no. 10, Article ID e3326, 2008.

[5] A. Spichler, B. L. Hurwitz, D. G. Armstrong, and B. A. Lipsky, "Microbiology of diabetic foot infections: from Louis Pasteur to 'crime scene investigation,' BMC Medicine, vol. 13, no. 1, article 2, 2015.

[6] J. W. Costerton, "Introduction to biofilm," International Journal of Antimicrobial Agents, vol. 11, no. 3-4, pp. 217-221, 1999.

[7] J. W. Costerton, P. S. Stewart, and E. P. Greenberg, "Bacterial biofilms: a common cause of persistent infections," Science, vol. 284, no. 5418, pp. 1318-1322, 1999.

[8] L. Hall-Stoodley, J. W. Costerton, and P. Stoodley, "Bacterial biofilms: from the natural environment to infectious diseases," Nature Reviews Microbiology, vol. 2, no. 2, pp. 95-108, 2004.

[9] N. Høiby, T. Bjarnsholt, M. Givskov, S. Molin, and O. Ciofu, "Antibiotic resistance of bacterial biofilms," International Journal of Antimicrobial Agents, vol. 35, no. 4, pp. 322-332, 2010.
[10] N. Høiby, O. Ciofu, and T. Bjarnsholt, "Pseudomonas aeruginosa biofilms in cystic fibrosis," Future Microbiology, vol. 5, no. 11, pp. 1663-1674, 2010.

[11] G. O’Toole, H. B. Kaplan, and R. Kolter, "Biofilm formation as microbial development," Annual Review of Microbiology, vol. 54, pp. 49-79, 2000.

[12] D. M. Citron, E. J. C. Goldstein, C. V. Merriam, B. A. Lipsky, and M. A. Abramson, "Bacteriology of moderate-to-severe diabetic foot infections and in vitro activity of antimicrobial agents," Journal of Clinical Microbiology, vol. 45, no. 9, pp. 2819-2828, 2007.

[13] S. M. McCarty and S. L. Percival, "Proteases and delayed wound healing," Advances in Wound Care, vol. 2, no. 8, pp. 438-447, 2013.

[14] B. A. Lipsky, "New developments in diagnosing and treating diabetic foot infections," Diabetes/Metabolism Research and Reviews, vol. 24, supplement 1, pp. S66-S71, 2008.

[15] D. A. Caminos and E. N. Durantini, "Photodynamic inactivation of Escherichia coli immobilized on agar surfaces by a tricationic porphyrin," Bioorganic and Medicinal Chemistry, vol. 14, no. 12, pp. 4253-4259, 2006.

[16] F. Cieplik, L. Tabenski, W. Buchalla, and T. Maisch, "Antimicrobial photodynamic therapy for inactivation of biofilms formed by oral key pathogens," Frontiers in Microbiology, vol. 5, article 405, 2014.

[17] T. Dai, Y.-Y. Huang, and M. R. Hamblin, "Photodynamic therapy for localized infections-state of the art," Photodiagnosis and Photodynamic Therapy, vol. 6, no. 3-4, pp. 170-188, 2009.

[18] S. A. G. Lambrechts, M. C. G. Aalders, and J. Van Marle, "Mechanistic study of the photodynamic inactivation of Candida albicans by a cationic porphyrin," Antimicrobial Agents and Chemotherapy, vol. 49, no. 5, pp. 2026-2034, 2005.

[19] M. R. Hamblin, D. A. O'Donnell, N. Murthy et al., "Polycationic photosensitizer conjugates: effects of chain length and Gram classification on the photodynamic inactivation of bacteria," Journal of Antimicrobial Chemotherapy, vol. 49, no. 6, pp. 941951, 2002.

[20] B. W. Henderson and T. J. Dougherty, "How does photodynamic therapy work?" Photochemistry and Photobiology, vol. 55, no. 1, pp. 145-157, 1992.

[21] A. P. Castano, T. N. Demidova, and M. R. Hamblin, "Mechanisms in photodynamic therapy: part one-photosensitizers, photochemistry and cellular localization," Photodiagnosis and Photodynamic Therapy, vol. 1, no. 4, pp. 279-293, 2004.

[22] V. Klepac-Ceraj, N. Patel, X. Song et al., "Photodynamic effects of methylene blue-loaded polymeric nanoparticles on dental plaque bacteria," Lasers in Surgery and Medicine, vol. 43, no. 7, pp. 600-606, 2011.

[23] M. N. Usacheva, M. C. Teichert, and M. A. Biel, "Comparison of the methylene blue and toluidine blue photobactericidal efficacy against gram-positive and gram-negative microorganisms," Lasers in Surgery and Medicine, vol. 29, no. 2, pp. 165-173, 2001.

[24] R. Pottier, R. Bonneau, and J. Joussot Dubien, "pH dependence of singlet oxygen production in aqueous solutions using toluidine blue as a photosensitizer," Photochemistry and Photobiology, vol. 22, no. 1-2, pp. 59-61, 1975.

[25] R. W. Redmond and J. N. Gamlin, "A compilation of singlet oxygen yields from biologically relevant molecules," Photochemistry and Photobiology, vol. 70, no. 4, pp. 391-475, 1999. 
[26] M. Canete, A. Villanueva, and A. Juarranz, "Uptake and photoeffectiveness of two thiazines in HeLa cells," Anti-Cancer Drug Design, vol. 8, no. 6, pp. 471-477, 1993.

[27] M. C. DeRosa and R. J. Crutchley, "Photosensitized singlet oxygen and its applications," Coordination Chemistry Reviews, vol. 233-234, pp. 351-371, 2002.

[28] M. Ogura, A. D. Abernethy, R. D. Blissett et al., "Photomechanical wave-assisted molecular delivery in oral biofilms," World Journal of Microbiology and Biotechnology, vol. 23, no. 11, pp. 1637-1646, 2007.

[29] N. S. Soukos, S. S. Socransky, S. E. Mulholland, S. Lee, and A. G. Doukas, "Photomechanical drug delivery into bacterial biofilms," Pharmaceutical Research, vol. 17, no. 4, pp. 405-409, 2000.

[30] M. Sharma, L. Visai, F. Bragheri, I. Cristiani, P. K. Gupta, and P. Speziale, "Toluidine blue-mediated photodynamic effects on staphylococcal biofilms," Antimicrobial Agents and Chemotherapy, vol. 52, no. 1, pp. 299-305, 2008.

[31] G. P. Tegos and M. R. Hamblin, "Phenothiazinium antimicrobial photosensitizers are substrates of bacterial multidrug resistance pumps," Antimicrobial Agents and Chemotherapy, vol. 50, no. 1, pp. 196-203, 2006.

[32] Y.-E. L. Koo, W. Fan, H. Hah et al., "Photonic explorers based on multifunctional nanoplatforms for biosensing and photodynamic therapy," Applied Optics, vol. 46, no. 10, pp. 19241930, 2007.

[33] W. Tang, H. Xu, E. J. Park, M. A. Philbert, and R. Kopelman, "Encapsulation of methylene blue in polyacrylamide nanoparticle platforms protects its photodynamic effectiveness," Biochemical and Biophysical Research Communications, vol. 369, no. 2, pp. 579-583, 2008.

[34] A. Khdair, B. Gerard, H. Handa, G. Mao, M. P. V. Shekhar, and J. Panyam, "Surfactant-polymer nanoparticles enhance the effectiveness of anticancer photodynamic therapy," Molecular Pharmaceutics, vol. 5, no. 5, pp. 795-807, 2008.

[35] M. D. Chavanpatil, A. Khdair, Y. Patil, H. Handa, G. Mao, and J. Panyam, "Polymer-surfactant nanoparticles for sustained release of water-soluble drugs," Journal of Pharmaceutical Sciences, vol. 96, no. 12, pp. 3379-3389, 2007.

[36] A. Khdair, D. Chen, Y. Patil et al., "Nanoparticle-mediated combination chemotherapy and photodynamic therapy overcomes tumor drug resistance," Journal of Controlled Release, vol. 141, no. 2, pp. 137-144, 2010.

[37] D. Nowis, M. Makowski, T. Stokłosa, M. Legat, T. Issat, and J. Golab, "Direct tumor damage mechanisms of photodynamic therapy," Acta Biochimica Polonica, vol. 52, no. 2, pp. 339-352, 2005.

[38] J. D. Bryers, "Medical biofilms," Biotechnology and Bioengineering, vol. 100, no. 1, pp. 1-18, 2008.

[39] T. G. St Denis, T. Dai, L. Izikson et al., "All you need is light, antimicrobial photoinactivation as an evolving and emerging discovery strategy against infectious disease," Virulence, vol. 2, no. 6, pp. 509-520, 2011.

[40] T.-F. C. Mah and G. A. O’Toole, "Mechanisms of biofilm resistance to antimicrobial agents," Trends in Microbiology, vol. 9, no. 1, pp. 34-39, 2001.

[41] P. S. Stewart and J. W. Costerton, "Antibiotic resistance of bacteria in biofilms," The Lancet, vol. 358, no. 9276, pp. 135-138, 2001.

[42] S. Wang, R. Gao, F. Zhou, and M. Selke, "Nanomaterials and singlet oxygen photosensitizers: potential applications in photodynamic therapy," Journal of Materials Chemistry, vol. 14, no. 4, pp. 487-493, 2004.

[43] M. Usacheva, S. K. Swaminathan, A. R. Kirtane, and J. Panyam, "Enhanced photodynamic therapy and effective elimination of cancer stem cells using surfactant-polymer nanoparticles," Molecular Pharmaceutics, vol. 11, no. 9, pp. 3186-3195, 2014.

[44] H. C. Junqueira, D. Severino, L. G. Dias, M. S. Gugliotti, and M. S. Baptista, "Modulation of methylene blue photochemical properties based on adsorption at aqueous micelle interfaces," Physical Chemistry Chemical Physics, vol. 4, no. 11, pp. 23202328, 2002.

[45] N. Kömerik and M. Wilson, "Factors influencing the susceptibility of Gram-negative bacteria to toluidine blue O-mediated lethal photosensitization," Journal of Applied Microbiology, vol. 92, no. 4, pp. 618-623, 2002.

[46] M. Bickel, G. Cimasoni, and E. Andersen, "Flow and albumin content of early (pre-inflammatory) gingival crevicular fluid from human subjects," Archives of Oral Biology, vol. 30, no. 8, pp. 599-602, 1985.

[47] R. Moseley, J. R. Hilton, R. J. Waddington, K. G. Harding, P. Stephens, and D. W. Thomas, "Comparison of oxidative stress biomarker profiles between acute and chronic wound environments," Wound Repair and Regeneration, vol. 12, no. 4, pp. 419-429, 2004.

[48] C. E. Davies, K. E. Hill, M. J. Wilson et al., "Use of 16 S ribosomal DNA PCR and denaturing gradient gel electrophoresis for analysis of the microfloras of healing and nonhealing chronic venous leg ulcers," Journal of Clinical Microbiology, vol. 42, no. 8, pp. 3549-3557, 2004.

[49] K. Gjødsbøl, J. J. Christensen, T. Karlsmark, B. Jørgensen, B. M. Klein, and K. A. Krogfelt, "Multiple bacterial species reside in chronic wounds: a longitudinal study," International Wound Journal, vol. 3, no. 3, pp. 225-231, 2006.

[50] G. A. James, E. Swogger, R. Wolcott et al., "Biofilms in chronic wounds," Wound Repair and Regeneration, vol. 16, no. 1, pp. 3744, 2008.

[51] A. S. Garcez, S. C. Núñez, N. Azambuja et al., "Effects of photodynamic therapy on gram-positive and gram-negative bacterial biofilms by bioluminescence imaging and scanning electron microscopic analysis," Photomedicine and Laser Surgery, vol. 31, no. 11, pp. 519-525, 2013.

[52] F. F. Sperandio, Y.-Y. Huang, and M. R. Hamblin, "Antimicrobial photodynamic therapy to kill Gram-negative bacteria," Recent Patents on Anti-Infective Drug Discovery, vol. 8, no. 2, pp. 108120, 2013

[53] S. DeLeon, A. Clinton, H. Fowler, J. Everett, A. R. Horswill, and K. P. Rumbaugh, "Synergistic interactions of Pseudomonas aeruginosa and Staphylococcus aureus in an in vitro wound model," Infection and Immunity, vol. 82, no. 11, pp. 4718-4728, 2014.

[54] K. J. Hendricks, T. A. Burd, J. O. Angelen, A. W. Simpson, G. D. Christensen, and B. J. Gainor, "Synergy between Staphylococcus aureus and Pseudomonas aeruginosa in a rat model of complex orthopaedic wounds," The Journal of Bone \& Joint SurgeryAmerican Volume, vol. 83, no. 6, pp. 855-861, 2001.

[55] L. Michaelis and S. Granick, "Metachromasy of basic dyestuffs," Journal of the American Chemical Society, vol. 67, no. 7, pp. 12121219, 1945.

[56] S. George and A. Kishen, "Photophysical, photochemical, and photobiological characterization of methylene blue formulations for light-activated root canal disinfection," Journal of Biomedical Optics, vol. 12, no. 3, Article ID 034029, 2007. 
[57] M. N. Usacheva, M. C. Teichert, C. E. Sievert, and M. A. Biel, "Effect of $\mathrm{Ca}^{2+}$ on the photobactericidal efficacy of methylene blue and toluidine blue against gram-negative bacteria and the dye affinity for lipopolysaccharides," Lasers in Surgery and Medicine, vol. 38, no. 10, pp. 946-954, 2006.

[58] T. N. Demidova and M. R. Hamblin, "Effect of cell-photosensitizer binding and cell density on microbial photoinactivation," Antimicrobial Agents and Chemotherapy, vol. 49, no. 6, pp. 2329-2335, 2005.

[59] M. A. Biel, "Photodynamic therapy of bacterial and fungal biofilm infections," Methods in Molecular Biology, vol. 635, pp. 175-194, 2010.

[60] C. N. Street, A. Gibbs, L. Pedigo, D. Andersen, and N. G. Loebel, "In vitro photodynamic eradication of Pseudomonas aeruginosa in planktonic and biofilm culture," Photochemistry and Photobiology, vol. 85, no. 1, pp. 137-143, 2009.

[61] D. Piacquadio and D. B. Nelson, "Alginates: a 'new' dressing alternative," Journal of Dermatologic Surgery and Oncology, vol. 18, no. 11, pp. 992-995, 1992. 

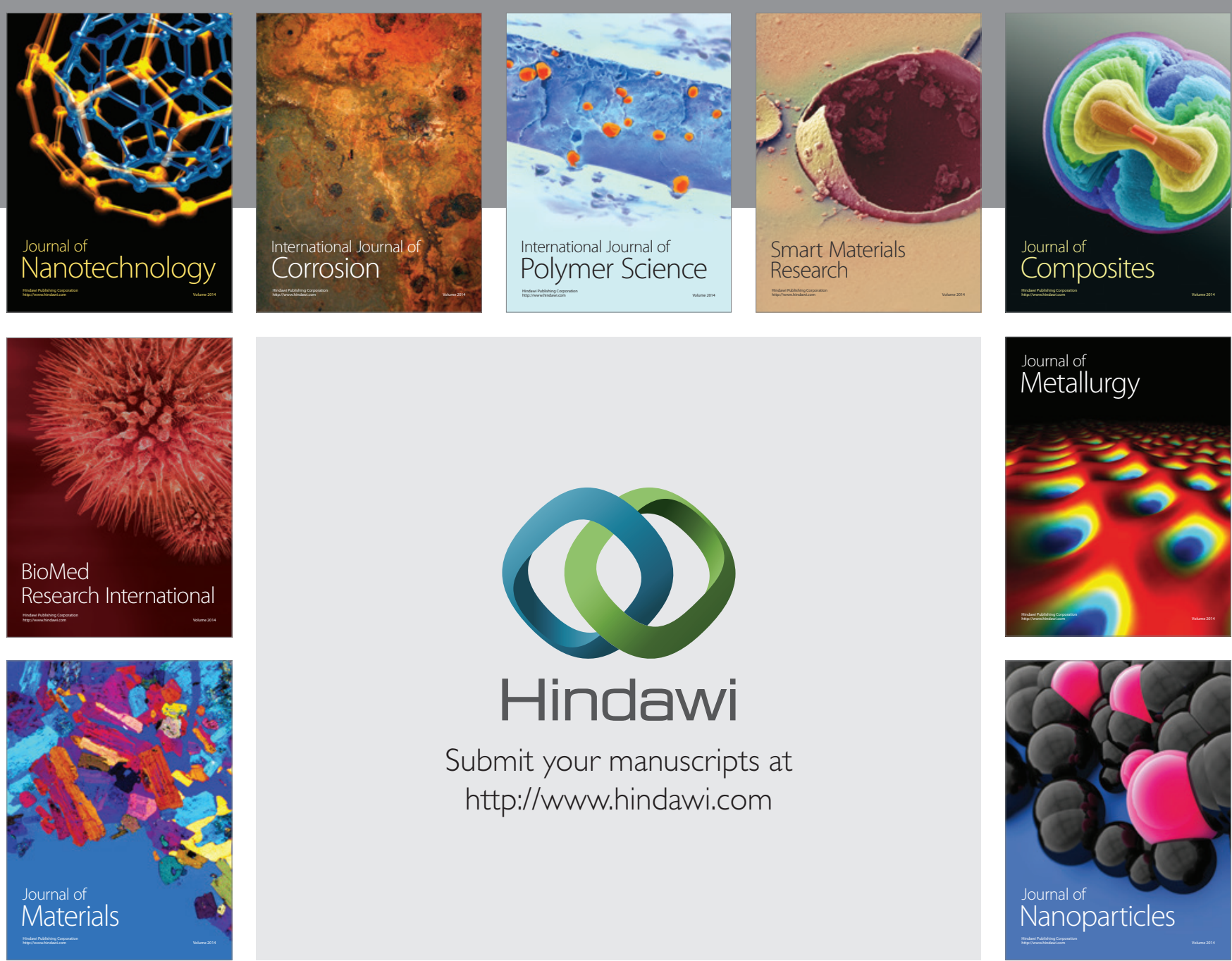

\section{Hindawi}

Submit your manuscripts at

http://www.hindawi.com

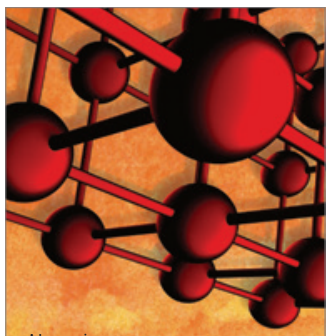

Materials Science and Engineering
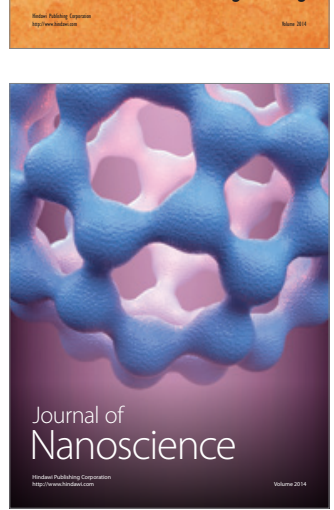
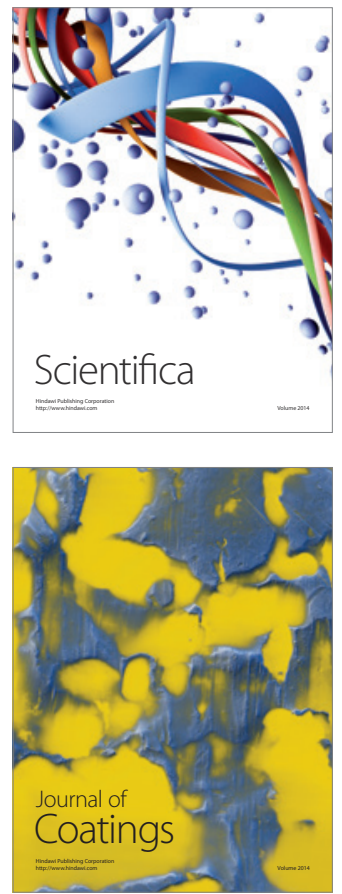
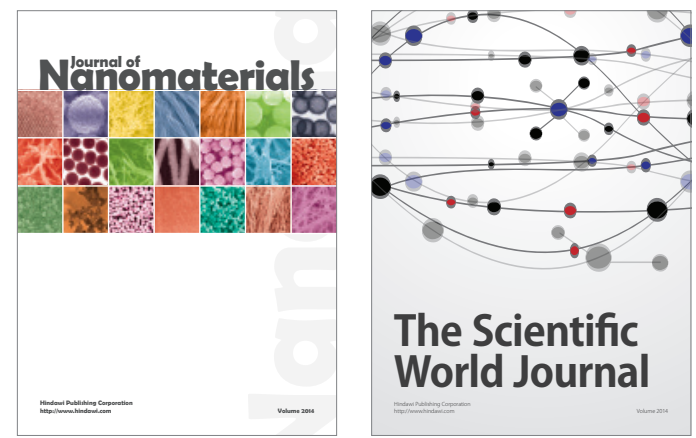

The Scientific World Journal
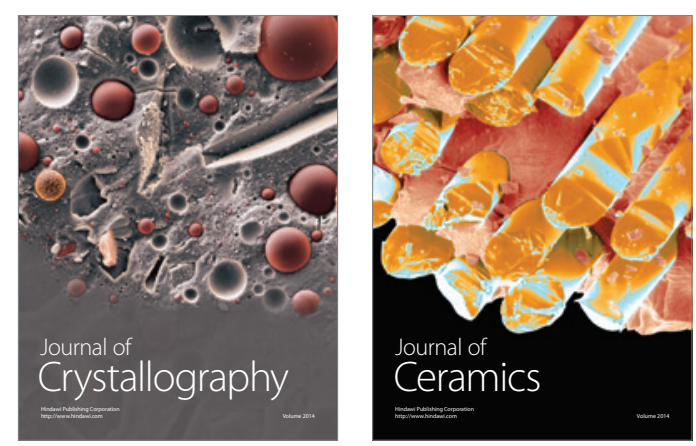
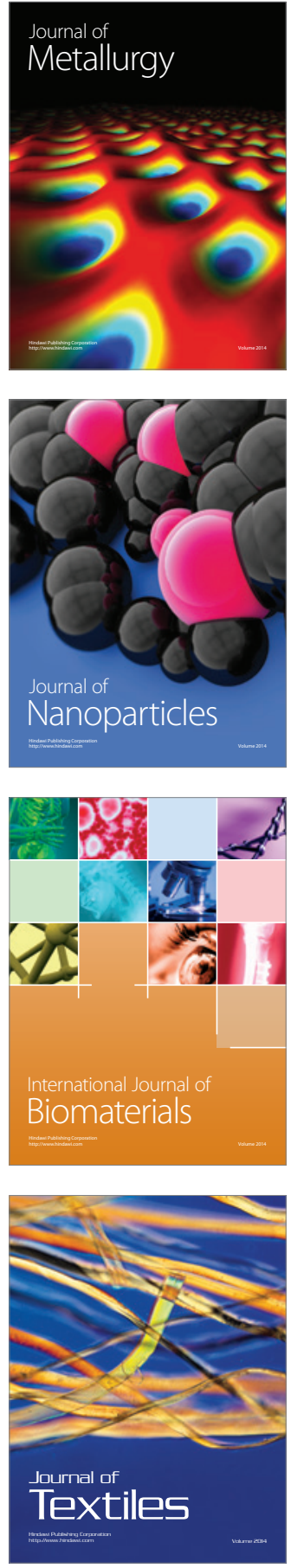